\title{
Effects of a former discharge of drill cuttings on the macrofauna community*
}

\author{
I. Kröncke ${ }^{1, * *}$, G. C. A. Duineveld ${ }^{2}$, S. Raak ${ }^{1}$, E. Rachor ${ }^{1}$, R. Daan ${ }^{2}$ \\ 'Alfred Wegener-Institute for Polar and Marine Research, Columbusstrasse, W-2850 Bremerhaven, Germany \\ ${ }^{2}$ Netherlands Institute for Sea Research, PO Box 59, 1790 AB Den Burg, Texel, The Netherlands
}

\begin{abstract}
As part of the ICES/IOC Bremerhaven Workshop, the macrofauna near a former drilling site for gas in the southern North Sea was investigated. Three years prior to the present investigation oil-contaminated drill cuttings had been discharged at the locality. Shortly after this operation had stopped, a macrofauna survey was carried out which showed effects at the drilling site and revealed a gradient of increase in species abundances and richness in the residual current direction from the discharge point. During the present study 9 stations along the same transect were sampled, up to a distance of $15000 \mathrm{~m}$ from the drilling site. In order to assess whether the initial gradient still existed, several univariate and multivariate methods were applied to the data set. Univariate methods showed decreasing trends in species number, biomass and total abundance within $1000 \mathrm{~m}$ (Stn E) of the drilling site. The abundances of some deep-burrowing species were low, particularly near the drilling site. However, differences between the stations were in many cases not highly significant. Cluster analysis and ordination with DECORANA and Multidimensional Scaling produced station patterns which point to a dependence between distance from the discharge site and the composition of the macrofauna. $A B C$ curves of the stations did not show any major changes along the transect. Photographic evidence that conditions in the upper sediment layer improved after 1988 is discussed together with the results of the meiofauna and bioassay work.
\end{abstract}

\section{INTRODUCTION}

During the Bremerhaven Workshop, an attempt was made to discover effects of discharges of oil-contaminated drill cuttings on the macofauna community. These discharges ceased 3 yr previously. An earlier analysis of the same community shortly after the discharge had taken place revealed clear-cut effects on both species abundances as well as the number of species (Daan et al. 1990). An extensive literature provides evidence that changes in macrofauna community structure can be used as an indicator for biological effects of contaminants and oil-pollution in particular (Gray et al. 1990). In their contribution to the GEEP/IOC Oslo Workshop. Gray et al. (1988) gave

- This is publication no. 518 of the Alfred Wegener-Institute for Polar and Marine Research

- Present address: Forschungsinstitut Senckenberg, Schleusenstr. 39a, W-2940 Wilhelmshaven, Germany examples of univariate community measures and of species-dependent (multivariate) methods which are currently used in conjunction with pollution effects studies. Multivariate analyses appear to be an especially sensitive tool for detecting changes in the structure of the faunal community (Warwick \& Clarke 1991).

\section{STUDY SITE AND METHODS}

Area of investigation. The investigation took place in March 1990 near a former drilling site (Stn A) north of Texel in the Dutch Sector of the North Sea (Daan et al. 1992). Water depth was about $42 \mathrm{~m}$ at all sampling stations. The surface sediment was uniform and could be characterized as muddy sand (Butler pers. comm.). In May 1987 an exploration drilling for gas had been carried out at the location, during which oil-based muds (OBM's) were used and discharged. After the ex- 
ploration the rig was removed and not replaced by a production platform. For the purpose of the present study, the abandoned drilling site was located and marked with a buoy by a ship of the North Sea Directorate (Rijkswaterstaat, Netherlands).

Sampling and sample treatment. On a transect parallel to the residual current direction $\left(060^{\circ}\right) 8$ stations were sampled at distances of $0,125,250,500,1000$, 2000 \& $5000 \mathrm{~m}$ designated A, B, C, D, E, F \& G respectively, with a reference Stn $\mathrm{R}$ at $15000 \mathrm{~m}$ from the drilling site. Distances were measured with radar. At each station 6 samples were taken with a $0.07 \mathrm{~m}^{2}$ box corer equipped with a circular corer to improve penetration and a valve on top of the core tube to prevent resuspension of the sediment during retrieval of the sample.

The samples were washed over a $1 \mathrm{~mm}$ sieve (round holes), and the residue was preserved in a buffered solution of $4 \%$ formalin. Three replicates were worked up at the NIOZ (Texel, Netheriands) and 3 at the AWI (Bremerhaven, Germany). In the laboratory the samples were washed a second time $(0.5 \mathrm{~mm}$ sieve $)$, to remove the remaining sediment, and stained with RoseBengal. A magnifying lens $(2 \times)$ was used during sorting. Animals were identified to species level, counted, and the total wet weight of each species was determined. The lengths of selected species were also measured.

Prior to sorting, the samples were subjected to a 'quick sorting' method in Bremerhaven, i.e. an inspection by eye for about $10 \mathrm{~min}$. During this time the specimens of larger species were counted and documented separately; small polychaetes and other 'difficult' organisms, however, were counted as groups.

Community analysis. Because of the wide variety of methods applicable to species-by-samples data, as for instance demonstrated in the reports on the GEEP/IOC Oslo Workshop, we made a necessary selection of methods on the basis of the earlier study by Daan et al. (1990) at the same locality, and recent papers by Gray et al. (1988, 1990) and Warwick \& Clarke (1991) on comparable pollution gradients.

Community descriptors: For each sample Hill's diversity numbers $N_{0}, N_{1}$ and $N_{2}$ (Hill 1973, see Soetaert \& Heip 1990) were calculated. Evenness was in accordance with Hill's notation defined as $N_{1} / N_{0}$ and $N_{2} / N_{1}$. Abundance-Biomass Comparison ( $A B C$ ) curves were constructed for each station in accordance with Warwick (1986) and Warwick et al. (1987), who argued that the relative position of the ranked curves provides an indication for pollution-induced stress (disturbance). In an undisturbed community the biomass curve is expected to lie above the abundance curve whereas under highly disturbed conditions the biomass curve lies beneath the abundance curve. In moderately disturbed cases the 2 curves are close together.
Statistics: For univariate measures, such as species number, abundance, diversity and evenness, notched box and whisker plots (McGill et al. 1978) were drawn which allow a multiple comparison between the median values of these measures on the transect. Trends in these variables along the transect were depicted by means of 'distance weighted least squares regression' curves (McLain 1971).

In their analysis of earlier data from the locality, Daan et al. (1990) used the ranked abundances of species in an ANOVA to test for differences between stations. Because of the smaller sample size in our study and consequently more zero values, we used the total abundance of each species at a station in a Friedman 2way analysis of variance. In addition to the ANOVA on ranked abundances, Daan et al. applied logit regression to detect gradients in the frequency of occurrence of species. The model in this case assumes an S-shaped increase of the expected frequency with increasing distance from the discharge site (see ter Braak \& Looman 1990). As Daan et al. (1990), we performed logit regression only on a subset of those species, which were present in more than $20 \%$ of the samples.

Multivariate techniques that were applied to the species-abundance/biomass matrix comprise cluster analysis, DEtrended CORrespondence ANAlysis (DECORANA; Hill 1979) and Multi-Dimensional Scaling (MDS; Kruskal \& Wish 1978). Where possible, data from each laboratory were analysed separately in order to minimize the potential effect due to sorting by the different laboratories. In cases where replicate data from one or both laboratories were combined into a single estimate for a station, a geometric mean was calculated, which is equivalent to the median in a lognormal distribution. For cluster analysis 2 types of similarity indices were used; the Bray-Curtis index (percentage dissimilarity; Bray \& Curtis 1957) and the Jaccard index (presence/absence of species; Jaccard 1912). Stations were clustered with the 'unweighted pair group method' (UPGMA; Romesburg 1984). The DECORANA ordination was an adapted version by ter Braak, which allows an adjustment for covariables (e.g. laboratory effects; see Ter Braak 1987). All the other statistical calculations and as well as the graphs were made with SYSTAT 5.0 (SYSTAT Inc., Evanston, USA).

\section{RESULTS}

\section{Diversity and biomass}

Fig. 1 a to $g$ shows that the number of species, total abundance, diversity $\left(N_{0}, N_{1}\right.$ and $\left.N_{2}\right)$ and biomass all decrease sharply when approaching the former discharge site from Stn F. The 2 diversity indices also drop 
at the other end of the transect, but less markedly. The 2 measures of evenness show a slight tendency to decrease at increasing distance from the discharge site. A more formal test of differences between stations with respect to the parameters in Fig. 1 is provided by the box and whisker plots of the values in Fig. $2 a$ to $g$. Although there is much overlap between comparison intervals belonging to successive stations, some significant differences can still be found between stations in
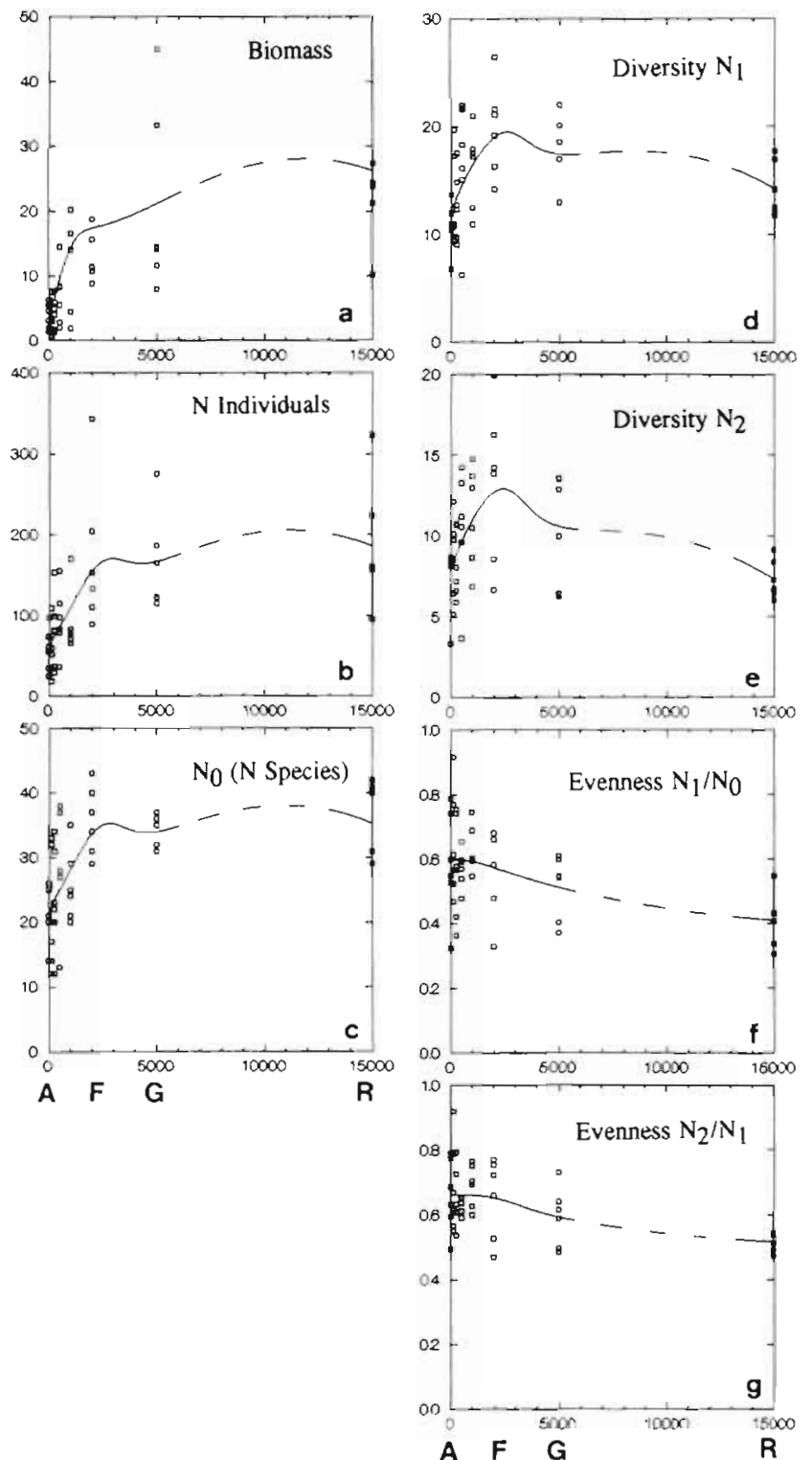

Fig. 1 Trends in community parameters along the transect. (a) Biomass ( $\mathrm{g}$ wet $\mathrm{wt} \mathrm{m}^{-2}$ ); (b) total number of individuals per sample; (c) number of species per sample (Hill's number $N_{0}$ ); (d) Hill's diversity number $N_{1}\left(\mathrm{e} H^{\prime}\right.$ with $H^{\prime}$ being the Shannon Wiener index); (e) Hill's diversity number $N_{2}$ (reciprocal of Simpson's index); (f) evenness defined as $N_{1} / N_{0} ;(g)$ evenness defined as $N_{2} / N_{1}$. Curves are fitted according to McLain (1971) the first (Stns A to E) and second part (Stns E to R) of the transect. This is for example the case with biomass, total abundance and number of species. Significant differences with respect to the diversity measures $N_{1}$ and $N_{2}$ are less numerous. Diversity at Stn $F$ is significantly higher than at the 2 stations at the extreme ends of the transect ( $A \& R$ ).

The ABC curves for the separate stations are depicted in Fig. 3. There are no marked differences in the relative positions of the curves between the stations, the biomass curves in all cases being above the abundance curves ('undisturbed').
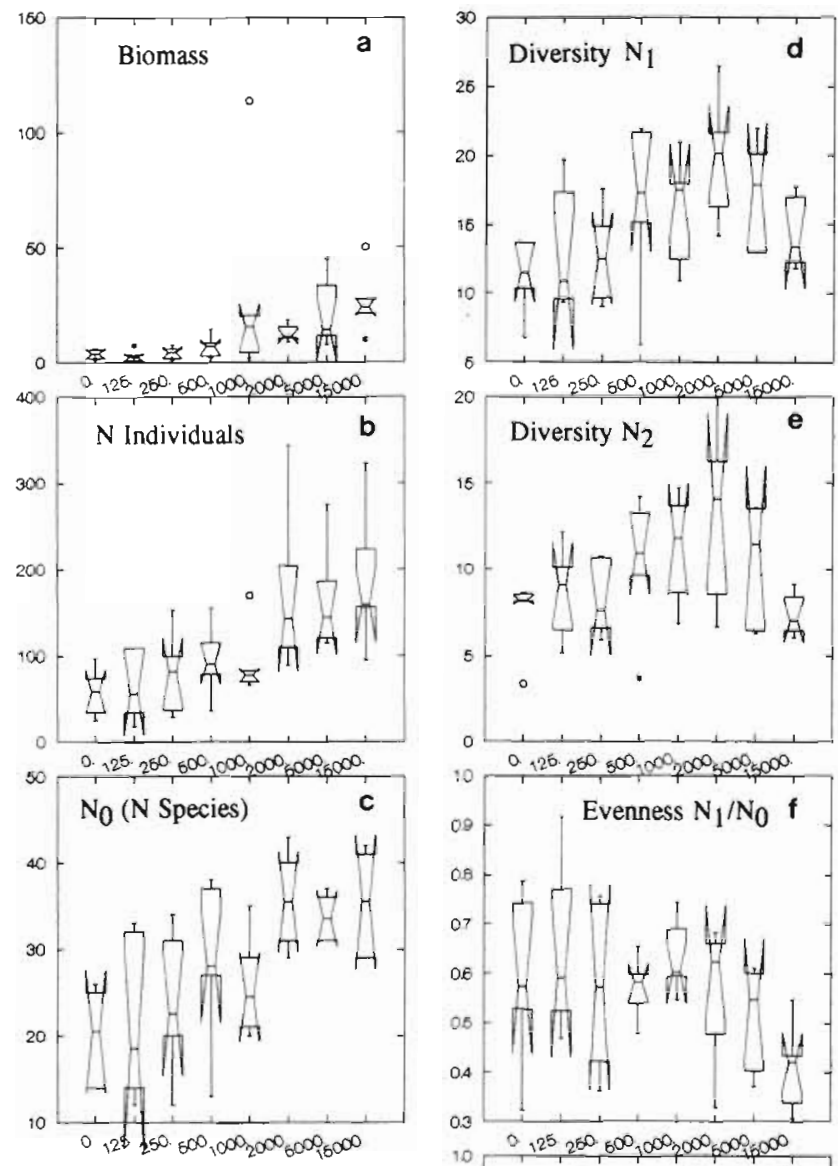

$A B C D E F G$

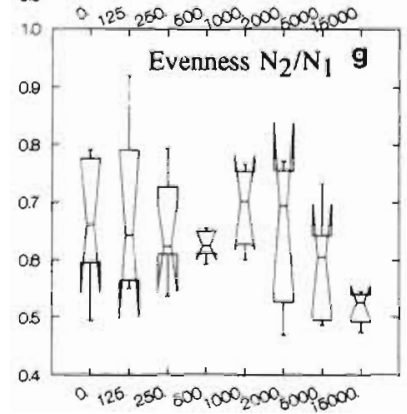

A B C D E F G R

Fig. 2. Box-whisker plots of community parameters shown in Fig. 1 (see legend). The levels where the box attains its full width mark the limits of the comparison interval 


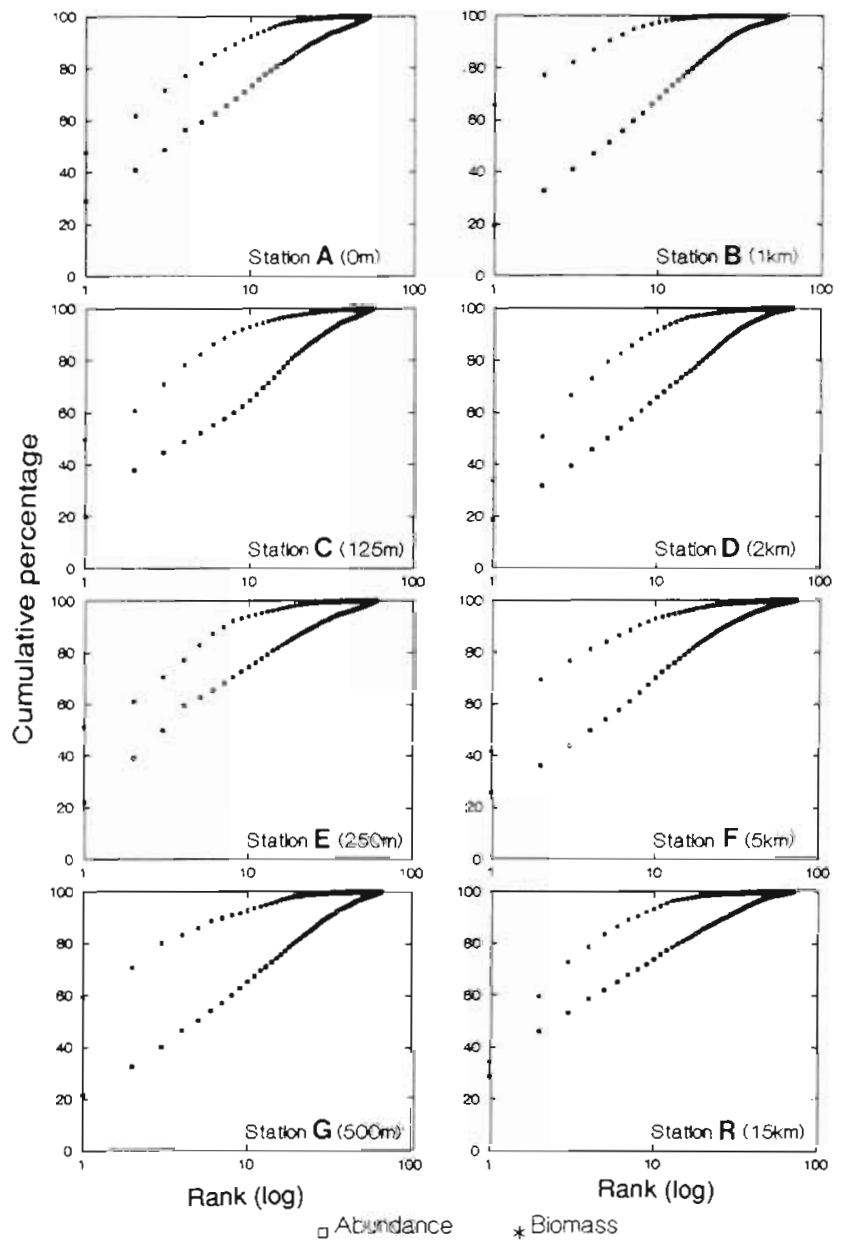

Fig. 3. Abundance-biomass curves for the stations

\section{Community analysis}

A Friedman 2-way analysis of variance was applied to the pooled abundances of the laboratories (i.e. sum of AWI and NIOZ abundances) and to the AWI and
Table 1. Results of Friedman 2-way analysis of variance. Only species occurring in more than $20 \%$ of the samples were used. Centre column: abundances of AWI and NIOZ, number of species $=118$. Right column: pooled abundances (sum of AWI and NIOZ), number of species $=59 . \cdots p<0.01$

\begin{tabular}{|lcc|}
\hline $\begin{array}{l}\text { Station } \\
\text { (m from discharge) }\end{array}$ & Sum of ranks & Sum of ranks \\
\hline 0 & 380 & \\
125 & 428 & 183 \\
250 & 452 & 196 \\
500 & 524 & 217 \\
1000 & 499 & 257 \\
2000 & 692 & 247 \\
5000 & 650 & 361 \\
15000 & 622 & 332 \\
Test statistic & $126{ }^{\circ}$ & 328 \\
\hline
\end{tabular}

NIOZ dibundances entered as separate replicates. The summed ranks of the stations are shown in Table 1 . In both cases there is a distinct increase in the sum of ranks from the first stations onwards, until maximum values are reached at $\operatorname{Stn} F$. At Stns $G \& R$ the ranks are again lower than at $S \operatorname{tn} F$, but still well above the inner stations. The test confirmed significant differences between the stations $(p<0.01)$.

The results of the cluster analyses with the geometric mean abundances per station (all data pooled) are depicted in Figs. $4 \& 5$. Although the classification of the stations differs depending on the similarity index used, some consistencies can be noted. In both dendrograms a cluster can be distinguished composed of the 3 outermost stations ( $F, G$ \& $R$ ). Stn A together with some neighbouring stations also shows a more or less separate position in both results. The dendrogram based on the Bray-Curtis index (Fig. 5) shows the greatest correspondence with the geographical distribution of the stations and the presumed pollution gradient.

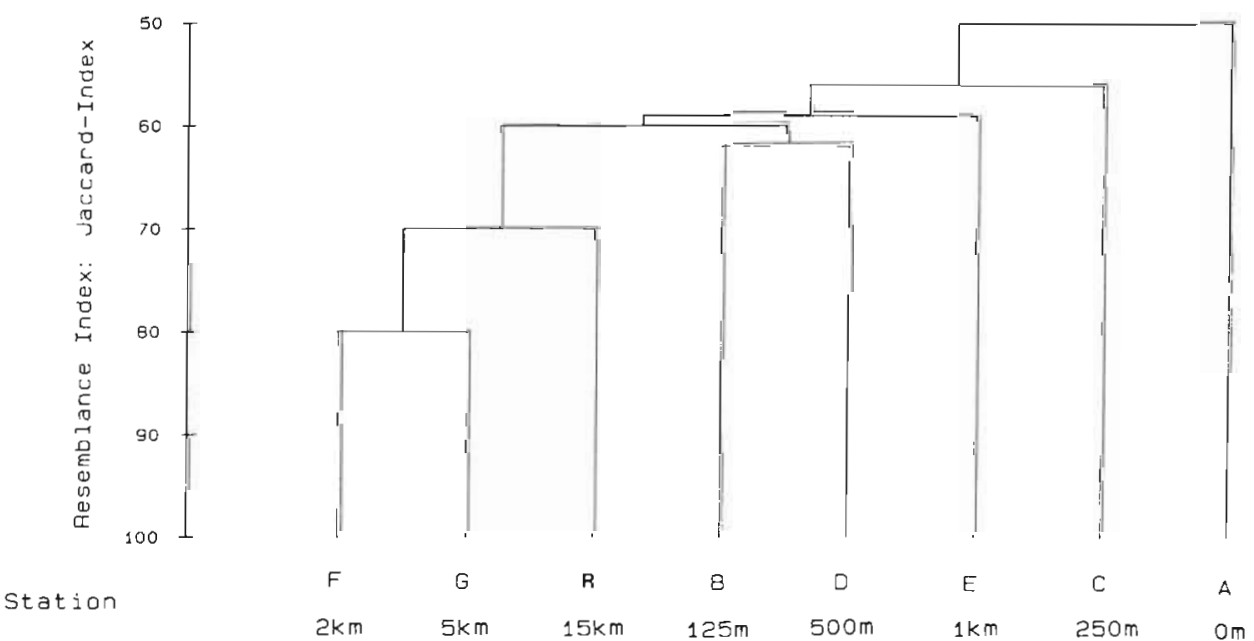

Fig. 4. Dendrogram resulting from cluster analysis of abundance loverall geometric means). Similarity is based on Jaccard's index 


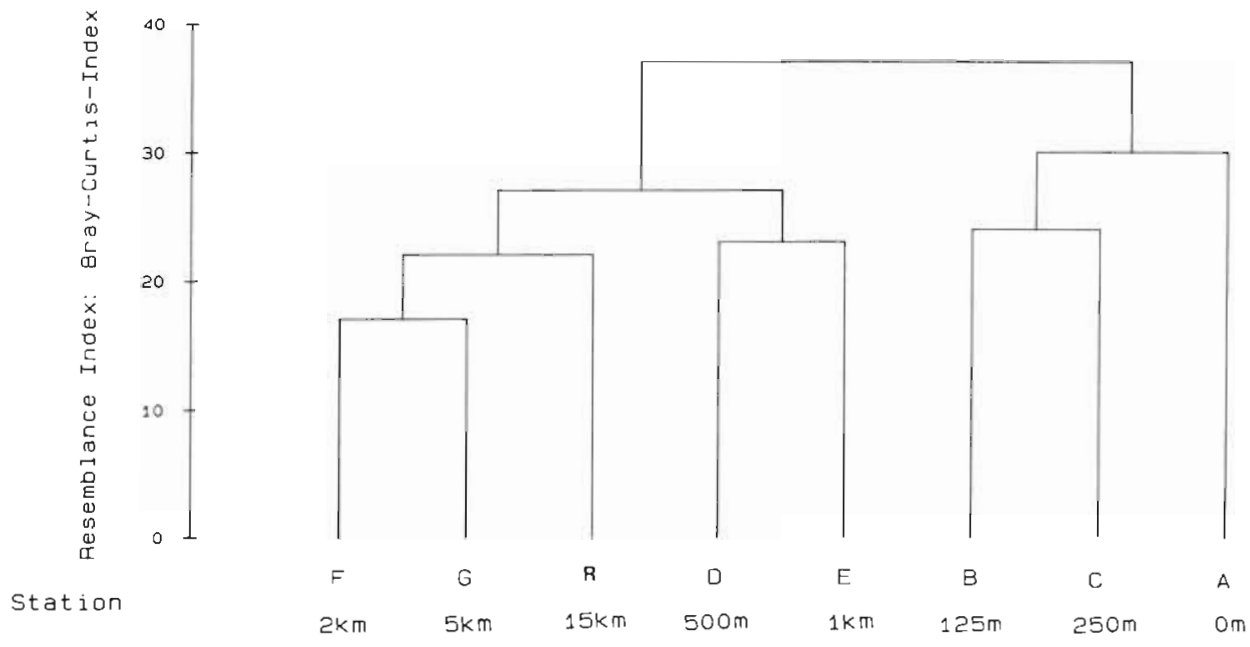

Fig. 5. Dendrogram resulting from cluster analysis of abundance (overall geometric means). Similarity is based on the Bray-Curtis index
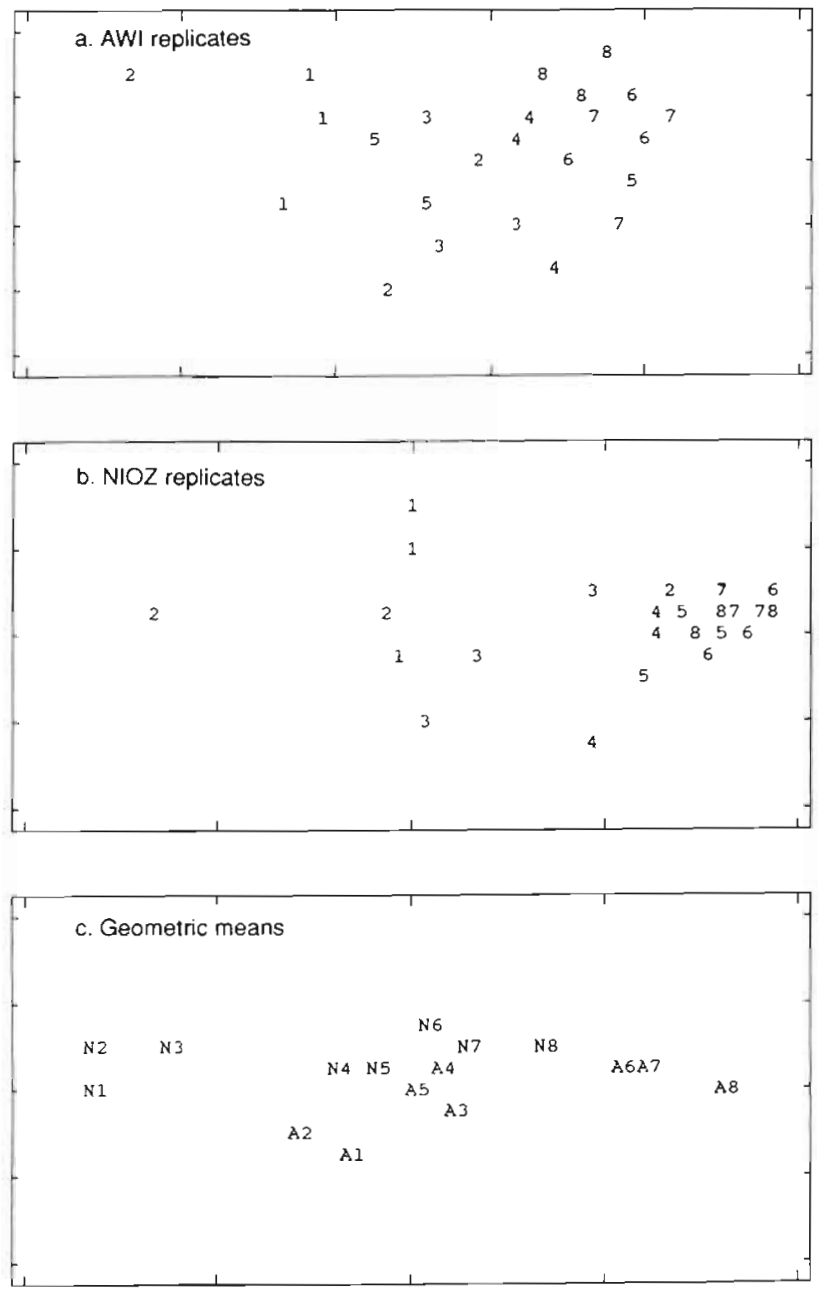

Fig. 6. Multi-dimensional scaling diagrams for samples analysed at 2 laboratories. (a) Replicates of AWI ( 3 per station); (b) replicates of $\mathrm{NIOZ}_{\text {; }}$ (c) geometric means of NIOZ (N) and AWI (A). Numbers 1 to 8 correspond to Stns A to G and R
The separate MDS-ordinations of the replicates of each laboratory (Fig. 6a, b) show that, despite a certain amount of mixing between replicates belonging to distant stations, there is a tendency for the samples to be arranged according to their rank distance. Ordination of the (geometric) means of both laboratories (Fig. 6c) reveals 2 unidimensional gradients, but the gradients are shifted relatively to each other. This configuration suggests the presence of a laboratory effect. A DECORANA ordination of the same set of means, whereby the laboratories were used as covariables (N for NIOZ and A for AWI), removed part of this effect (Fig. 7). The stations are again arranged in order of their distances from the discharge site, but the 2 means are now closer together, notably those belonging to the more distant stations.

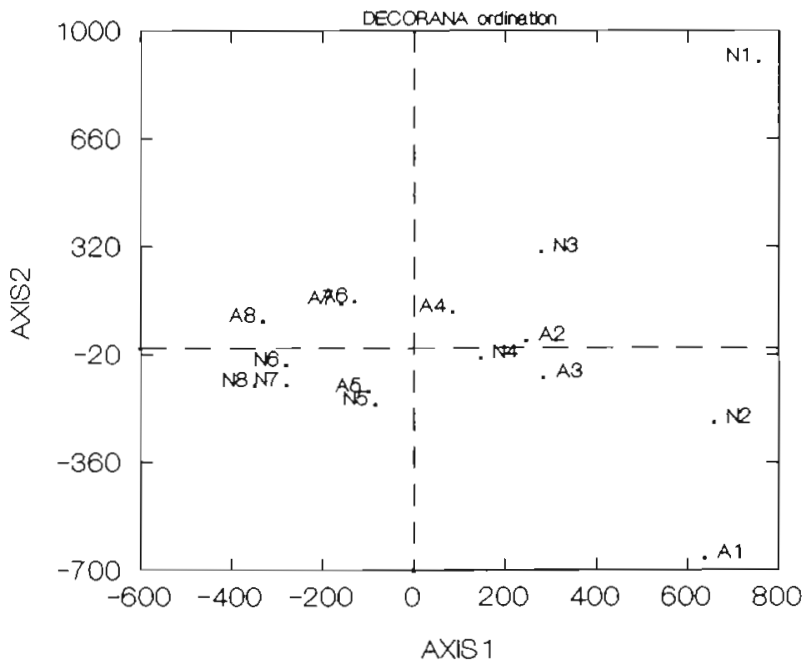

Fig. 7. DECORANA ordination of NIOZ and AWI means. Laboratories ( $\mathrm{N}=\mathrm{NIOZ;} \mathrm{A}=\mathrm{AWI}$ ) were used as covariables 


\section{Single species}

Table 2 lists the species which occurred with significantly reduced frequencies near the discharge site in 1988 (Daan et al. 1990). The right hand section summarizes the results of logit regression with the 1990 data. For a number of species there is still a significant S-shaped gradient detectable. In some species the initial gradient has either disappeared (Amphiura filiformis, Diastylis bradyi) or has become less or non-significant (e.g. Lumbrineris latreilli). For one species not mentioned by Daan et al. (1990), the sipunculid Golfingia elongata, a significant gradient was found in 1990
It is likely that species which occur with a reduced frequency near the discharge site tend to have an, on average, lower abundance in the corresponding part of the transect (logit regression). On the other hand, in the absence of a gradient in frequency of occurrence, a species could still display a gradient in abundance. Fig. 8 shows abundance trends of some selected species from Table 2. The often suggestive trends in Fig. 8 are in most species not supported by formally consistent and significant differences between (median) abundances as indicated by the box and whisker plots in Fig. 9. Even for species with conspicuous zero occurrences near the discharge site, like the burrowing ech-
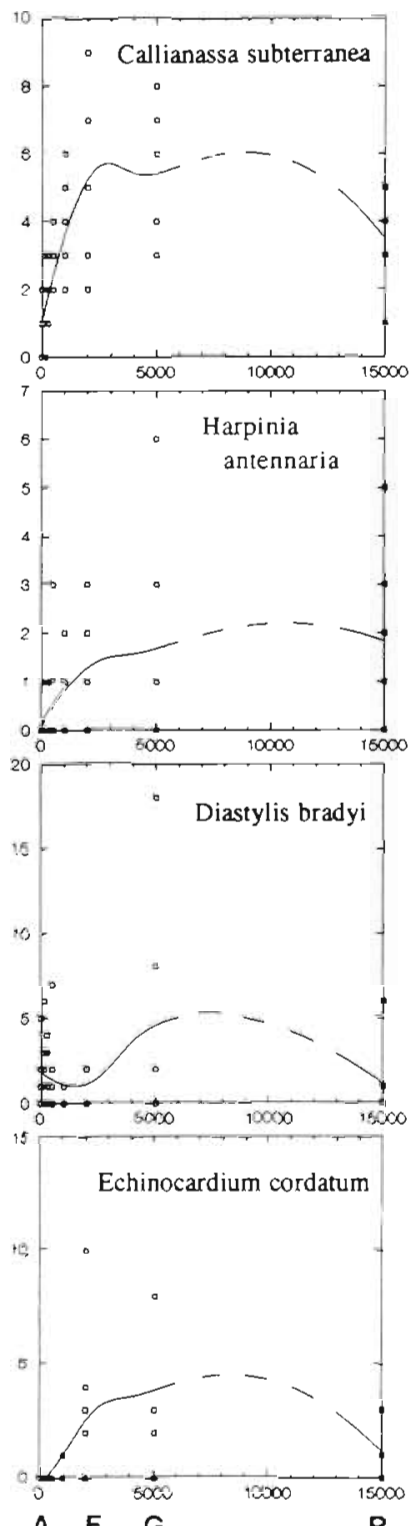
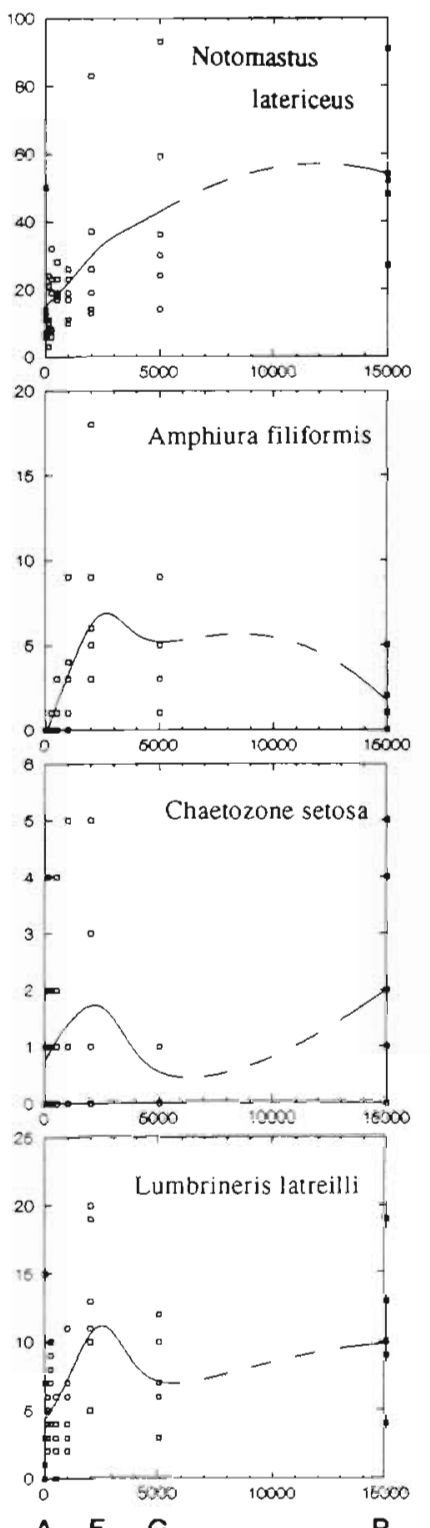

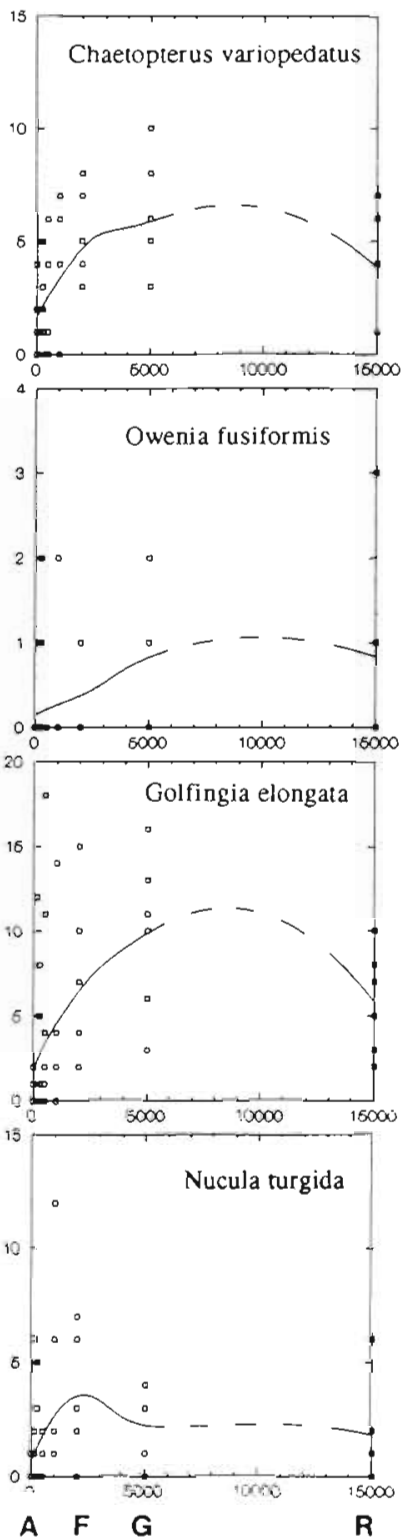

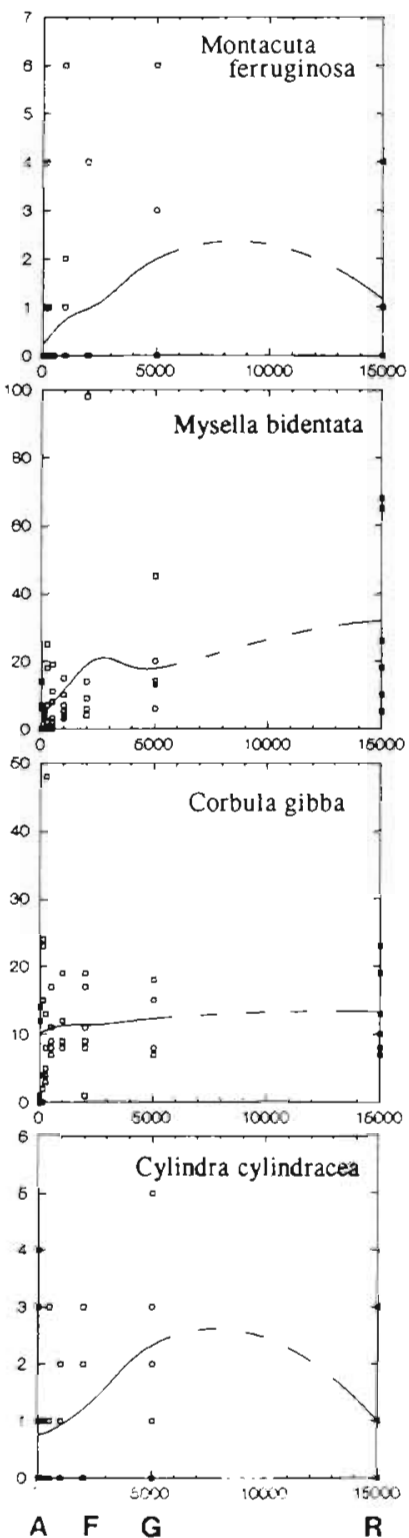

Fig. 8. Abundance trends of selected species with a significant gradient in density away from the discharge site in either June 1988 or in March 1990 or in both surveys (see Table 2). Curves are fitted according to McLain (1971) 
inoid Echinocardium cordatum and the deep-burrowing polychaete Notomastus latericeus, the box and whisker plots do not show highly significant differences. Among the very few species showing straightforward or weaker trends in density are the deepburrowing shrimp Callianassa subterranea and the sipunculid Golfingia elongata.

Of 3 selected species, Amphiura filiformis, Mysella bidentata and Corbula gibba, length-frequency distributions were plotted to see whether the disturbed sites were inhabited by relatively young populations. It was found that in all 3 species the position of the main modal size class is not markedly different along the

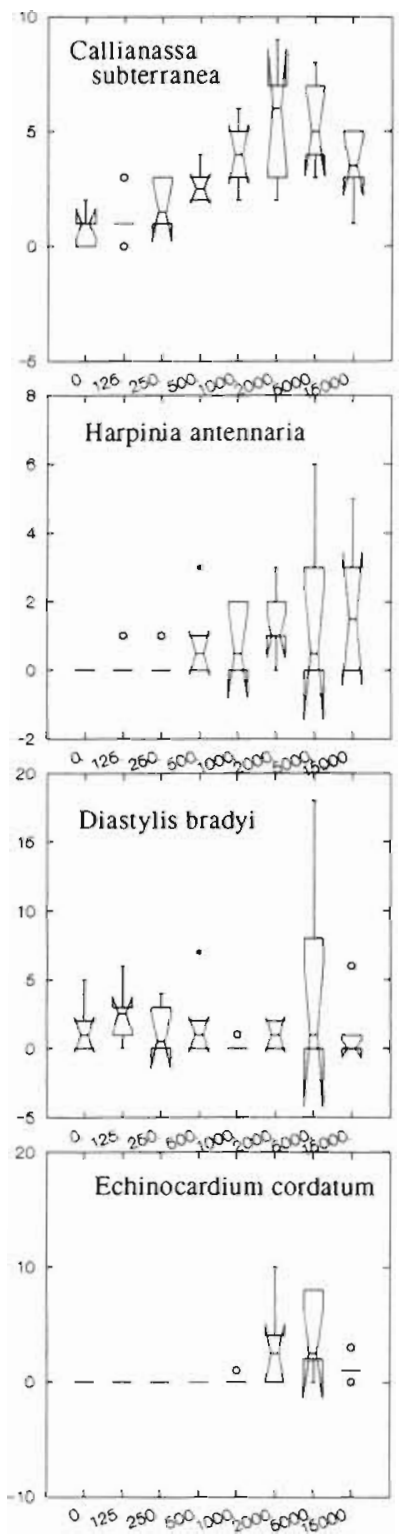

A B C DEFGR

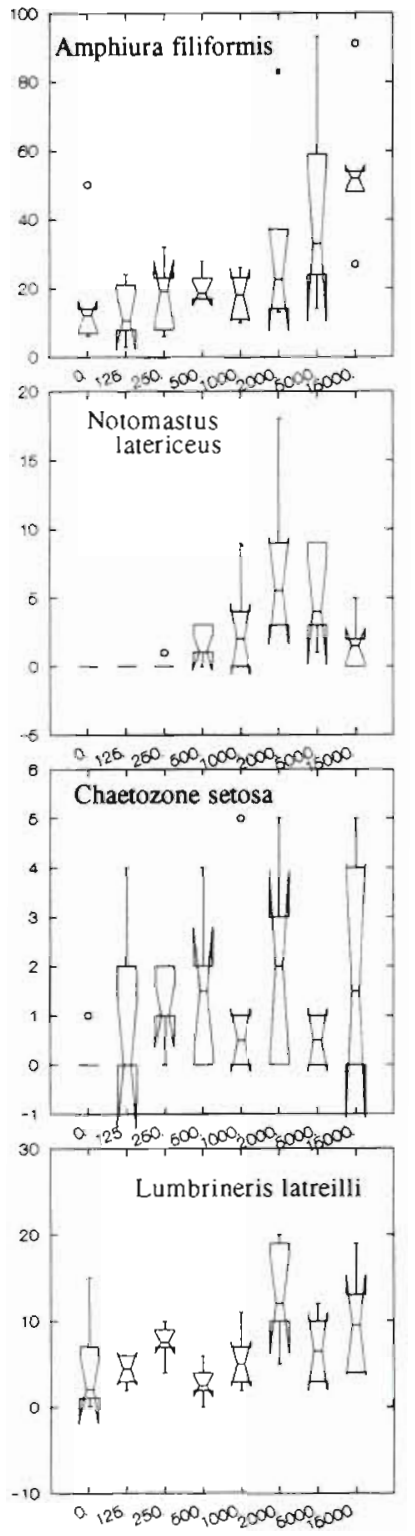

A B C DEF G R transect. However, in A. filiformis an increased proportion of older individuals (>5 mm) was found at $S \operatorname{tn} R$ (Fig. 10).

\section{Quick-sorting method}

The 'quick-sorting method' revealed a slight increase in the number of identifiable species with increasing distance from the pollution source, being 6 in the range from Stns $A$ to $C$ and rising to 10 at Stn $R$ (Table 3). For some large, conspicuous species like Echinocardium cordatum it was possible to give an in-
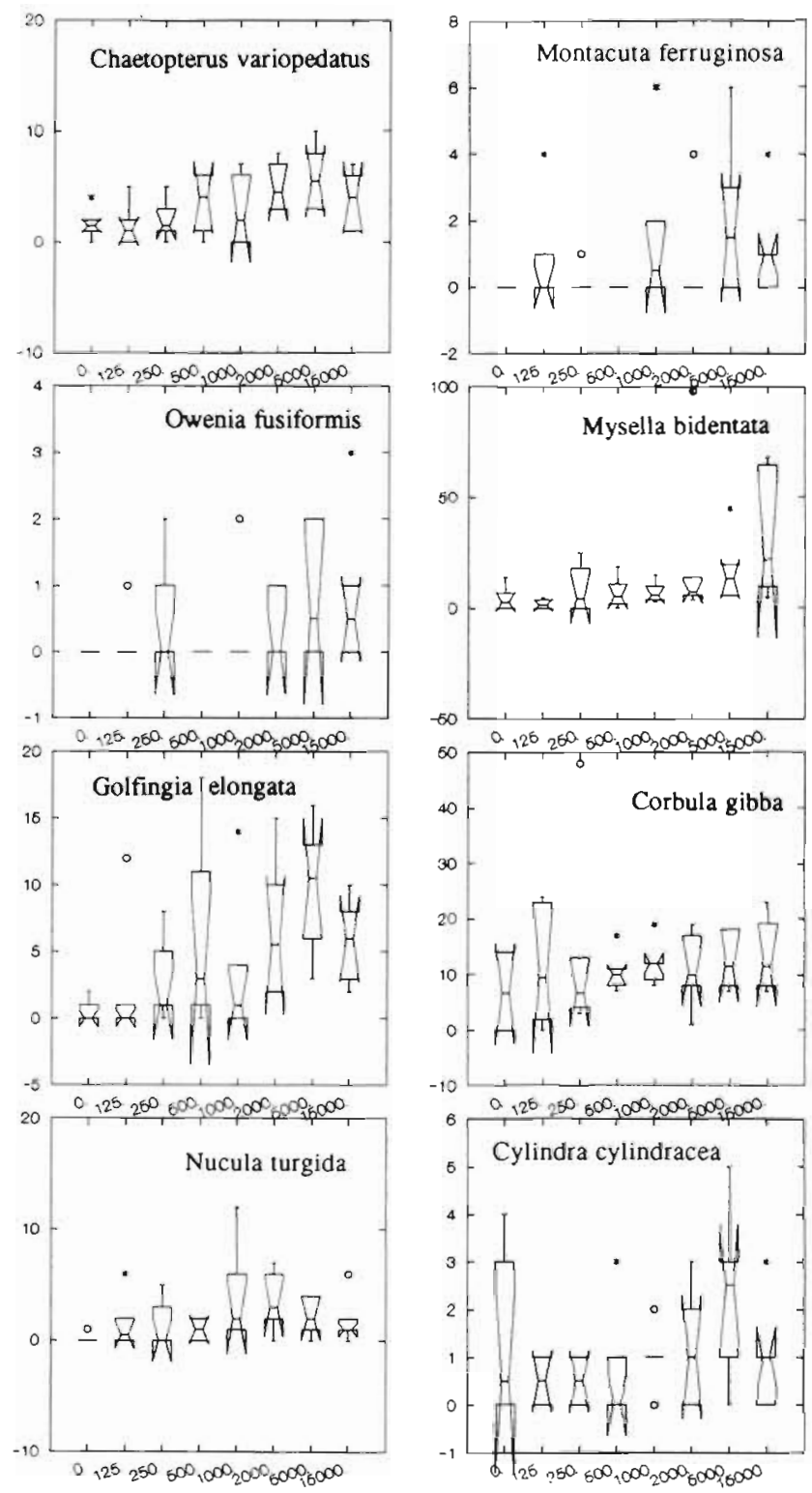

A B C DEF G R

Fig. 9. Box-whisker plots of the abundances of the same set of species dealt with in Fig. 8 


\section{Amphiura filiformis}
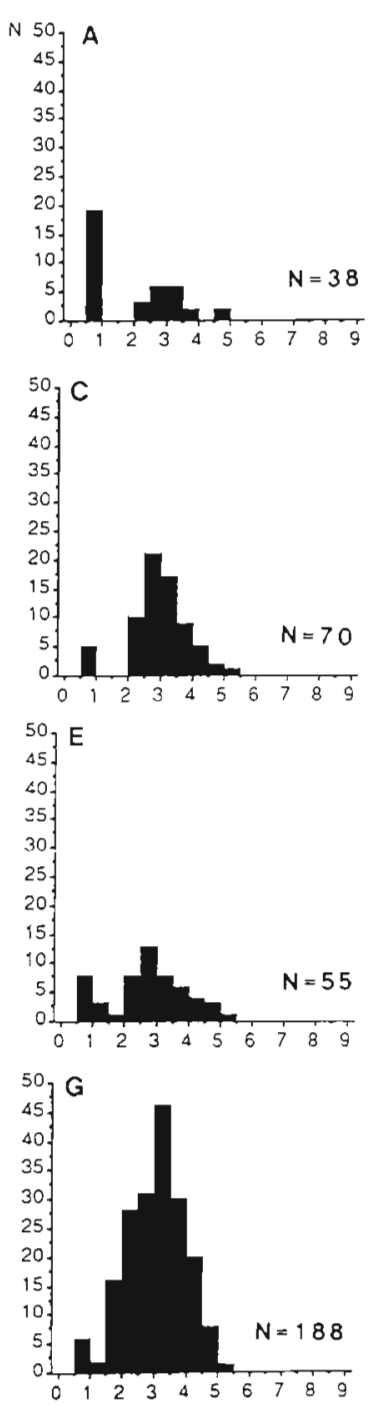

$\operatorname{disc} \emptyset(\mathrm{mm})$
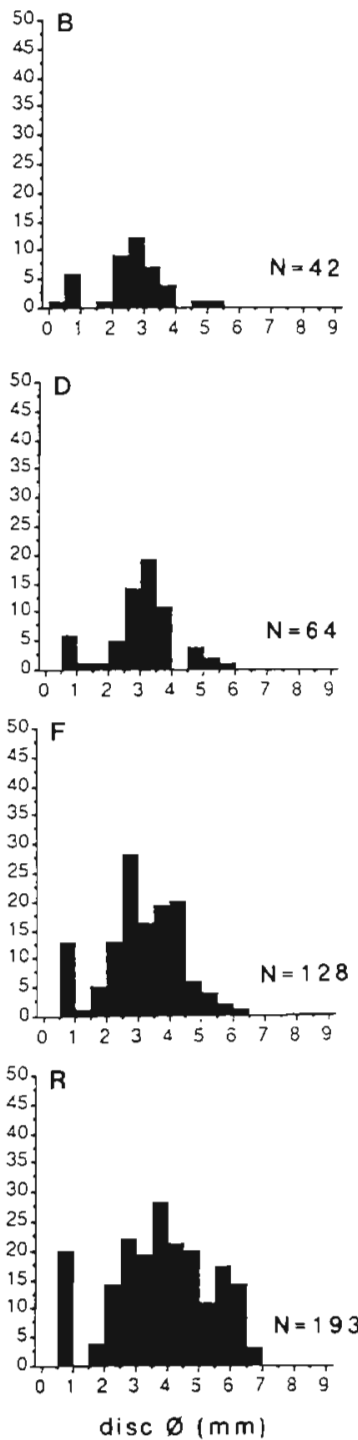

Fig. 10. Size-frequency distributions of the ophiuoid Amphiura filiformis at the 8 stations along the transect

dication of their abundances. Especially for species such as Amphiura filiformis, which can attain substantial density, variations along the transect (i.e. Stn R) can be detected.

\section{DISCUSSION}

During the ICES/IOC Bremerhaven Workshop a comparison was made of biological methods to detect the effects of pollution. The choice of the present former discharge site of oil-based drilling muds offered several advantages. Firstly, the initial pollution gradi- ent and effects were already defined (Daan et al. 1992), which enabled us to delimit the sampling effort to one transect in the residual current direction. Secondly, the site was located in a rather uniform environment with respect to depth and sediment composition. A disadvantage might have been the time that had passed between the discharge and our sampling. It could be assumed that in the meantime the majority of the fauna had recovered from the adverse effects of the discharge, and that the initial, strong gradients had weakened. On the other hand, this situation presented a test of the sensitivity of our methods.

Summarizing the results, we can, nevertheless, say that there was still a gradient in the macrofauna community structure similar to that found shortly after the discharge had taken place (Daan et al. 1990). This conclusion is based mainly on the multivariate analyses which all produced a clear differentiation between the stations near the former discharge site and those furthest away. Univariate measures, i.e. species numbers, abundance and biomass, showed equivocal trends, with depressed values near Stn A but differences along the transect either not very explicit, or more often not significant at high levels, as shown by the

Table 2. Species showing a significant density gradient (logit regression). Sign of the gradient (+/) and significance level $(\%)$ are indicated. +: Increasing densities off the location: -: decreasing densities off location. ns: not significant (critical level $=5 \%) ;=$ : not present in sufficient numbers

\begin{tabular}{|c|c|c|c|c|}
\hline \multirow[t]{2}{*}{ Species } & \multicolumn{2}{|c|}{1988 survey } & \multicolumn{2}{|c|}{1990 survey } \\
\hline & Sign & $\begin{array}{l}\text { Signf. } \\
\text { level }\end{array}$ & Sign & $\begin{array}{l}\text { Signf } \\
\text { level }\end{array}$ \\
\hline Harmothoe longisetis & + & 0.5 & - & ns \\
\hline Anaitides groenlandica & - & 5 & $=$ & \\
\hline Glycinde nordmanni & + & 5 & $=$ & \\
\hline Lumbrineris latreilli & + & 5 & + & ns \\
\hline Lumbrineris fragilis & + & 1 & - & ns \\
\hline Spiophanes bombyx & + & 0.1 & $=$ & \\
\hline Chaetopterus variopedatus & + & 0.5 & + & 5 \\
\hline Chaetozone setosa & + & 0.5 & + & ns \\
\hline Notomastus latericeus & + & 0.1 & + & 5 \\
\hline Heteromastus filiform!s & + & 0.1 & $=$ & \\
\hline Owenia fusiformis & + & 5 & + & 5 \\
\hline Nucula turgida & + & 0.1 & + & 5 \\
\hline Montacuta ferruginosa & + & 0.1 & + & 5 \\
\hline Mysella bidentata & + & 1 & + & 0.1 \\
\hline Abra alba & + & 5 & $=$ & \\
\hline Cingula nitida & + & 5 & $=$ & \\
\hline Cylichna cylindracea & + & 5 & + & ns \\
\hline Callianassa subterranea & + & 0.1 & + & 1 \\
\hline Diastylis bradyi & + & 5 & - & ns \\
\hline Harpinia antennaria & + & 0.1 & + & 5 \\
\hline Amphiura filiformis & + & 0.1 & & ns \\
\hline Echinocardium cordatum & + & 5 & + & 0.1 \\
\hline Golfingia elongata & $=$ & & + & 0.1 \\
\hline
\end{tabular}




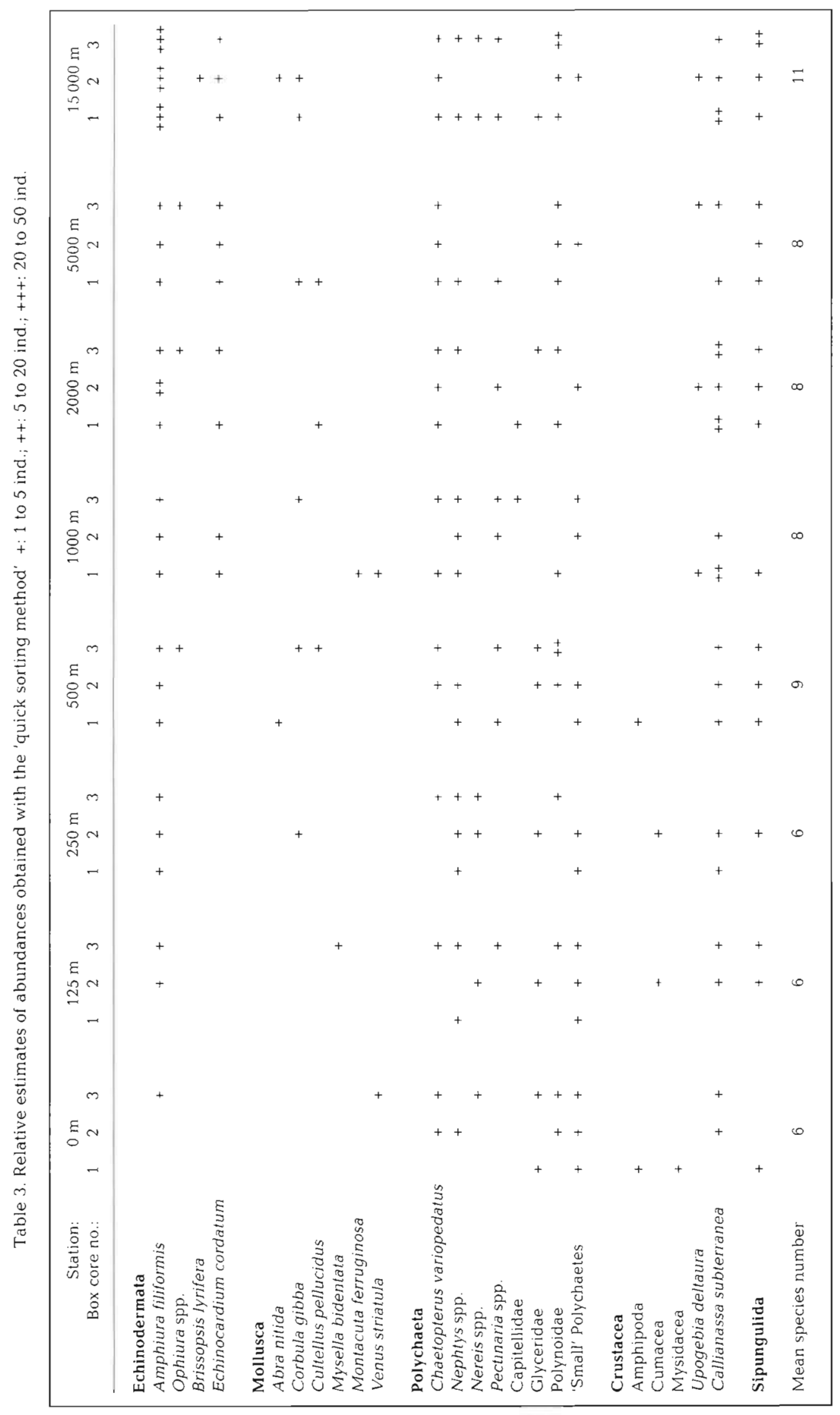


box-whisker plots. In some cases this insignificance may be explained by the increased variance resulting from the laboratory effect. Inspection of the data sets showed that the small ( 1 to $2 \mathrm{~mm}$ ), but sometimes abundant, bivalves Mysella bidentata and Corbula gibba were found in lower densities by one laboratory. The box-whisker plots of these species and of densitydependent measures such as total abundance, diversity and evenness may have been negatively influenced by this laboratory effect.

On the other hand, the decrease of the diversities and the abundances of different species at $\operatorname{Stn} R$, $15000 \mathrm{~m}$ away from the drilling site, might not be due to the contamination gradient, but e.g. to a sediment gradient or large-scale variations in dispersion. Unfortunately grain size analyses were performed only up to Stn G; and Stn R was not studied in 1988.

The laboratory effect probably also affected the outcome of the MDS ordination of the 2 data sets (Fig. $6 \mathrm{c}$ ). An analysis of the species contributions to the BrayCurtis dissimilarity between replicate means, i.e. AWI and NIOZ means of the same station, showed that notably in the case of the first 3 Stns ( $A, B$ \& $C$ ), the bivalves (Mysella bidentata and Corbula gibba) accounted for a large part of the total dissimilarity. Removing these 2 species produced a MDS ordination with replicate means of the first 3 stations lying close together. However, more important with respect to the existence of a gradient was the fact that the separate sets of means showed similar patterns, demonstrated also by DECORANA.

In contrast with the multivariate methods, the $\mathrm{ABC}$ curves did not yield any indication for a gradient in the level of disturbance. According to Warwick et al. (1987) the configuration of the ABC curves in Fig. $3 \mathrm{im}$ plies that all stations form part of an undisturbed community. The position of the biomass curves in the present study is explained by the biomass dominance of a few large species like Chaetopterus variopedatus. Given the small weights and even numerical distribution of the other species near the discharge site, a few specimens of such large species are sufficient to keep the biomass curve above the abundance curve. The $\mathrm{ABC}$ method does not seem to be an appropriate method for detecting the subtle gradients investigated here (see also Kröncke \& Rachor 1992).

The 'quick-sorting' method was carried out in order to demonstrate that time-consuming and laborious sorting is not always necessary to assess whether a site is still disturbed or not. A prerequisite for the application of this method is that one has knowledge of a wide spectrum of species, especially species that are sensitive to the type of disturbance in question, and that these species can be easily identified on board. An example is Echinocardium cordatum, which Daan et al.
(1990) showed to be very sensitive to oil contamination. As the densities of these large and conspicuous species in samples of the size that we used are generally low, they do not permit sound statistical analysis. However, by quickly sorting a greater number of samples at the expense of the post-cruise sorting, one can effectively and quickly establish whether a site is still affected.

In general, the phenomena we found have often been reported with regard to macrofauna investigations around oil rigs, where OBM's have been discharged (Addy et al. 1984, Davies et al. 1984, Kingston 1987, 1990, Daan et al. 1990). Mair et al. (1987) found a reduction of species richness within a distance of 500 to $1000 \mathrm{~m}$ (Stns D to E) and up to $3000 \mathrm{~m}$ (Gray et al. 1990) of a drilling site related to high concentrations of hydrocarbons. The sediment in their study, muddy sand as in our case, still contained $73 \%$ of the initial concentration 9 mo after the driliing operation had stopped. The levels of hydrocarbons in surface sediment samples along our transect in March 1990 were rather uniform and showed no increase close to the drilling site (Cofino et al. 1992). A comparison between photographs of the sediment taken by Daan et al. (1990) shortly after the drilling operation and in-situ sediment profiles taken by Rumohr \& Schomann (1992) with a REMOTS camera during the present study point to an improvement of conditions. The sediment cores taken by Daan et al. (1990) near the drilling site $(50 \mathrm{~m})$ had a clear (oil-)polluted surface layer. The REMOTS photographs of the sediment profile showed that the whole transect was covered with a layer of light-coloured muddy sand. Traces of presumably polluted sediment in the form of dark-coloured patches were only found in the deeper layers near the discharge site. At more distant stations the deeper layers always had a uniformly grey colour. Thus the REMOTS pictures show that the polluted surface sediment was replaced or covered with fresh sediment in the period after 1988 and especially during the very heavy storms in the winter of 1990 . This new layer probably allowed species such as Mysella bidentata and Montacuta ferruginosa, which were absent at the time of Daan's study, to settle near the discharge site. Even passive immigration by transportation together with the transposed sediments has to be considered. This holds true also for the meiofauna, the results of which did not show a significant trend along the former pollution gradient (Gee et al. 1992). The likewise not very conclusive results of the sediment bioassay work may also be explained by the translocations and changes of the surface sediments tested.

Raised densities of opportunistic species, as mentioned by Daan, close to the gas rig, which are typical for active drilling sites (Kingston 1990), were not found 
in our study. Therefore, our results together with the chemical and meiofauna data indicate that the area with its fauna is recovering from the pollution by the former oil-based drilling mud discharges.

Altogether, our investigation showed that structural parameters of the macrofauna community can be used as indicators for a former point source pollution, even in such cases of ongoing recovery.

A complete set of benthic community data for the workshop is available from M. Carr, Plymouth Marine Laboratory, UK

Acknowledgements. Thanks are due to the crews of the research vessels 'Aurelia' and 'Holland' for their help with sampling.

\section{LITERATURE CITED}

Addy, J. M., Hartley, J. P, Tibbets, P. J. C. (1984). Ecological effects of low toxicity oil-based mud drilling in the Beatrice Oilfield. Mar. Pollut. Bull. 15: 429-436

Braak, C. J. F. ter (1987). Ordination. In: Jongman, R. H. G., ter Braak, C. J. F., van Tongeren, O F. R. (eds.) Data analysis in community and landscape ecology. Pudoc, Wageningen, p. 91-173

Braak, C. J. F. ter, Looman, C. W. N. (1987). Regression. In: Jongman, R. H. G., ter Braak, C. J. F., van Tongeren, O. F. R. (eds.) Data analysis in community and landscape ecology. Pudoc, Wageningen, p. 29-77

Bray, J. R., Curtis, J. T. (1957). An ordination of the upland forest of Southern Wisconsin. Ecol. Monogr. 27: 225-349

Cofino, W. P., Smedes, F., de Jong, S. A., Abarnou, A., Boon, J. P., Oostingh, I., Davies, I. M., Klungsøyr, J., Wilhelmsen, S., Law, R. J., Whinnett, J. A., Schmidt, D., Wilson, S. (1992). The chemistry programme. Mar. Ecol. Prog. Ser. 91: $47-56$

Daan, R., van het Groenewoud, H., de Jong, S. A., Mulder, M. (1992). Physico-chemical and biological features of a drilling site in the North Sea, 1 year after discharges of oil-contaminated drill cuttings. Mar. Ecol. Prog. Ser. 91: 37-45

Daan, R., Lewis, W. E., Mulder, M. (1990). Biological effects of discharged oil-contaminated drill cuttings in the North Sea. NIOZ-Rapport 1990-5: $79 \mathrm{pp}$

Davies, J. M., Addy, J. M., Blackman, R. A., Blanchard, J. R., Ferbrache, J. E., Moore, D. C., Somerville, H. J., Whitehead, A., Wilkinson, T. (1984). Environmental effects of the use of oil-based drilling muds in the North Sea. Mar. Pollut. Bull. 15: 363-370

Gee, J. M., Austen, M., De Smet, G., Ferraro, T., McEvoy, A., Moore, S., Van Gausbeki, D., Vincx, M., Warwick, R. M. (1992). Soft sediment meiofauna community responses to environmental pollution gradients in the German Bight and at a drilling site of the Dutch coast. Mar. Ecol. Prog. Ser. 91: 289-302

Gray, J. S., Aschan, M., Carr, M. R., Clarke, K. R., Green, R. H., Pearson, $T H$., Rosenberg, R., Warwick, R. M. (1988). Analysis of community attributes of the benthic macrofauna of Frierfjord/Langesundfjord and in a mesocosm experiment. Mar. Ecol. Prog. Ser. 46: 151-165

Gray, J. S., Clarke, K. R., Warwick, R. M., Hobbs, G. (1990). Detection of initial effects of pollution on marine benthos: an example from the Ekofisk and Eldfisk oilfields, North Sea. Mar. Ecol. Prog. Ser. 66: 285-299

Hill, M. O. (1973). Diversity and evenness: a unifying notation and its consequences. Ecology 54:427-432

Hill, M. O. (1979). DECORANA - a FORTRAN program for detrended correspondence analysis and reciprocal averaging. Cornell University, Ithaca, New York

Jaccard, P. (1912). The distribution of the flora of the alpine zone. New Phytol, 11:37-50

Kingston, P. F. (1987). Field effects of platform discharges on benthic macrofauna. Phil. Trans. R. Soc. Lond. B 316: $545-565$

Kingston, P. F. (1990). Impact of offshore oil production installations on the benthos of the North Sea. ICES C.M./ Mini: 7, $6 \mathrm{pp}$

Kröncke, I., Rachor, E. (1992). Macrofauna investigations along a transect from the inner German Bight towards the Dogger Bank. Mar. Ecol. Prog. Ser. 91: 269-276

Kruskal, J. B., Wish, M. (1978). Multidimensional scaling. Sage Publications, Beverly Hills

Mair, J. McD., Matheson, I., Applebee, G. F. (1987). Offshore macrobenthic recovery in the Murchison Field following termination of drill-cuttings discharge. Mar. Pollut. Bull. 18: 628-634

McGill, R., Tukey, J. W., Larsen, W. A. (1978). Variations of box plots. Am. Statist. 32: 12-16

McLain, D. H. (1971). Drawing contours from arbitrary data points. The Computer Journal 17(4): 318-324

Romesburg, C. H. (1984). Cluster analysis for researchers. Wadsworth, Belmont

Rumohr, H., Schomann, H. (1992). REMOTS sediment profiles around an exploratory drilling rig in the southern North Sea. Mar. Ecol. Prog. Ser. 91: 303-311

Soetaert, K., Heip, C. (1990). Sample-size dependence of diversity indices and the determination of sufficient sample size in a high-diversity deep-sea environment. Mar. Ecol. Prog. Ser. 59: 305-307

Warwick, R. M. (1986). A new method for detecting pollution effects on marine macrobenthos communities. Mar. Biol. 92: $557-562$

Warwick, R. M., Pearson, T. H., Ruswahyuni (1987). Detection of pollution effects on marine macrobenthos: further evaluation of the species abundance/biomass method. Mar. Biol. 95: 193-200

Warwick, R. M., Clarke, K. R. (1991). A comparison of some methods for analysing changes in benthic community structure. J. mar. biol. Ass. U.K. 71: 225-244 